\title{
Magnetic Resonance Imaging of Diverticular Disease and its Association with Adipose Tissue Compartments and Constitutional Risk Factors in Subjects from a Western General Population
}

\section{Zusammenhang zwischen Divertikulose mittels Magnetresonanztomografie Körperfettkompartimenten und konstitutionellen Risikofaktoren in einem westlichen Normalkollektiv}

Authors

Corinna Storz ${ }^{1}$, Susanne Rospleszcz ${ }^{2}$, Esther Askani ${ }^{3}$, Theresa Rothenbacher ${ }^{4}$, Jakob Linseisen ${ }^{5,6}$, Helmut Messmann $^{7}$, Carlo N. De Cecco ${ }^{8}$, Jürgen Machann, 10, 11, Lena Sophie Kiefer ${ }^{4}$, Stefanie Elser ${ }^{4}$, Wolfgang Rathmann ${ }^{12}$, Annette Peters ${ }^{2}, 13,14,15$, Christopher L. Schlett ${ }^{3}$, Fabian Bamberg ${ }^{3}$

Affiliations

1 Department of Neuroradiology, Medical Center University of Freiburg, Faculty of Medicine, Freiburg, Germany

2 Institute of Epidemiology, Helmholtz Centre Munich, German Research Center for Environmental Health, Neuherberg, Germany

3 Department of Diagnostic and Interventional Radiology, Medical Center - University of Freiburg, Freiburg, Germany

4 Department of Diagnostic and Interventional Radiology, University Hospital Tuebingen, Tuebingen, Germany

5 Chair of Epidemiology, Ludwig-Maximilians University of Munich, UNIKA-T Augsburg, Augsburg, Germany

6 IRG Clinical Epidemiology, Helmholtz Centre Munich, German Research Center for Environmental Health, Neuherberg, Germany

7 Department of Internal Medicine III, Klinikum Augsburg, Augsburg, Germany

8 Division of Cardiothoracic Imaging, Department of Radiology and Imaging Sciences, Emory University Hospital, Atlanta, GA, USA

9 Section on Experimental Radiology, Department of Diagnostic and Interventional Radiology, University Hospital Tuebingen, Tuebingen, Germany

10 Institute for Diabetes Research and Metabolic Diseases (IDM) of the Helmholtz Center Munich at the University of Tuebingen, Germany

11 German Center for Diabetes Research (DZD), Tuebingen, Germany

12 Department of Biometry and Epidemiology, German Diabetes Center, Duesseldorf, Germany

13 German Center for Cardiovascular Disease Research (DZHK e. V.), Munich, Germany

14 Institute for Cardiovascular Prevention, LudwigMaximilians-University-Hospital, Munich, Germany

15 Chair of Epidemiology, Ludwig-Maximilians-University, Munich, Germany
Key words

epidemiology, diverticular disease, abdomen, MRI, metabolic Disorders

received 27.01.2020

accepted 21.06.2020

published online 12.08.2020

Bibliography

Fortschr Röntgenstr 2021; 193: 33-41

DOI 10.1055/a-1212-5669

ISSN 1438-9029

(C) 2020. Thieme. All rights reserved.

Georg Thieme Verlag KG, Rüdigerstraße 14,

70469 Stuttgart, Germany

Correspondence

Dr. Fabian Bamberg

Abteilung Röntgendiagnostik, Radiologische

Universitätsklinik, Hugstetter Straße 55, 79106 Freiburg,

Germany

fabian.bamberg@uniklinik-freiburg.de

\section{ZUSAMMENFASSUNG}

Ziel Ziel dieser Studie war es, den Zusammenhang zwischen asymptomatischer Divertikulose und Körperfettkompartimenten, Hepatosteatose sowie konstitutionellen Risikofaktoren, erhoben mittels Magnetresonanztomografie (MRT), in einem westlichen Normalkolletkiv zu untersuchen.

Material und Methoden Gesunde, asymptomatische Teilnehmer wurden in eine prospektive Fall-Kontroll-Studie eingeschlossen und mittels 3-Tesla-Ganzkörper-MRT untersucht. Anhand einer isotropen VIBE-Dixon-Sequenz des Abdomens wurden das Ausmaß einer Divertikulose (Anzahl der Divertikel pro Kolonsegment) sowie das Volumen des viszeralen, subkutanen und totalen Fettgewebes (VAT, SAT und TAT) bestimmt. Zusätzlich wurde der Grad einer Hepatosteatose (hepatic proton density fat fraction (hepatic PDFF)) mittels einer Multi- 
echo-T1w-Sequenz ermittelt. Konstitutionelle kardiometabolische Risikofaktoren wurden erhoben und univariate und multivariate Analysen durchgeführt.

Ergebnisse Insgesamt wurden 371 Teilnehmer in die Analyse eingeschlossen (58,2\% Männer; 56,2 \pm 9,2 Jahre alt). Basierend auf den MRT-Ergebnissen hatten 154 Probanden (41,5\%) eine Divertikulose, 62 (17\%) eine fortgeschrittene Divertikulose. Probanden mit fortgeschrittener Divertikulose hatten im Vergleich zu Probanden ohne Divertikulose einen höheren BMI (BMI: 29,9 $\pm 5,1$ vs. 27,5 $\pm 4,6$; $p<0,001$ ). Alle Fettkompartimente waren bei Teilnehmern mit fortgeschrittener Divertikulose erhöht (bspw. VAT: 6,0 $\pm 2,8$ vs. 4,2 $\pm 2,6$ und SAT: $9,2 \pm 3,6$ vs. $7,8 \pm 3,6$, jeweils $p<0,001)$. Ebenfalls wurde eine signifikant höhere Hepatosteatose bei Teilnehmern mit fortgeschrittener Divertikulose gefunden (hepatic PDFF: $4,9(2,7,11,4]$ vs. $6,1(5,5,14,6) ; p=0,002)$.

Schlussfolgerung Die fortgeschrittene Divertikulose geht signifikant mit höheren metabolischen Fettgewebsveränderungen, insbesondere vermehrten Körperfettkompartimenten und erhöhten BMI-Werten einher. Dies lässt einen metabolischen Pathomechanismus in der Entstehung der Divertikulose vermuten.

\section{Kernaussagen:}

- Das Vorhandensein einer Divertikulose ist mit konstitutionellen Risikofaktoren (bspw. BMI) assoziiert.

- Vermehrte Körperfettmengen und Hepatosteatose sind mit einer Divertikulose assoziiert.

- Unsere Ergebnisse lassen einen geteilten Pathomechanismus durch kardiometabolische Veränderungen und das Vorhandensein einer Divertikulose vermuten.

- Die MRT ermöglicht die Erfassung von Körperfettkompartimenten, einer Hepatosteatose sowie einer Divertikulose und ermöglicht somit eine Identifikation von Risikofaktoren in einem asymptomatischen Krankheitsstatus.

\section{ABSTRACT}

Purpose To determine the association of asymptomatic diverticular disease as assessed by magnetic resonance imaging (MRI) with adipose tissue compartments, hepatic steatosis and constitutional risk factors within a cohort drawn from a Western general population.

Materials and Methods Asymptomatic subjects enrolled in a prospective case-control study underwent a 3 Tesla MRI scan, including an isotropic VIBE-Dixon sequence of the entire trunk. The presence and extent of diverticular disease were categorized according to the number of diverticula in each colonic segment in a blinded fashion. The amount of visceral, subcutaneous, and total adipose tissue (VAT, SAT, and TAT) was quantified by MRI. Additionally, the degree of hepatic steatosis, indicated as hepatic proton density fat fraction (hepatic PDFF) was determined using a multi-echo T1w sequence. Constitutional cardiometabolic risk factors were obtained and univariate and multivariate associations were calculated.

Results A total of 371 subjects were included in the analysis ( $58.2 \%$ male, $56.2 \pm 9.2$ years). Based on MRI, 154 participants $(41.5 \%)$ had diverticular disease with 62 cases $(17 \%)$ being advanced diverticular disease. Subjects with advanced diverticular disease had a significantly higher body mass index (BMI) (BMI: $29.9 \pm 5.1$ vs. $27.5 \pm 4.6, \mathrm{p}<0.001$; respectively). Furthermore, all adipose tissue compartments were increased in subjects with advanced diverticular disease (e.g. VAT: $6.0 \pm 2.8$ vs. $4.2 \pm 2.6$ and SAT: $9.2 \pm 3.6$ vs. $7.8 \pm 3.6$, all $\mathrm{p}<0.001$, respectively). Similarly, subjects with advanced diverticular disease had significantly higher hepatic PDFF (4.9 $[2.7,11.4]$ vs. $6.1[5.5,14.6], p=0.002$ )

Conclusion Advanced diverticular disease is associated with an increased volume of adipose tissue compartments and BMI, which may suggest a metabolic role in disease development.

\section{Key Points:}

- Diverticular disease is associated with constitutional risk factors such as BMI.

- Excess of adipose tissue compartments and hepatic steatosis are associated with the prevalence of diverticular disease.

- Our results suggest a shared pathological pathway of cardiometabolic alterations and the prevalence of diverticular disease.

- MRI is feasible for the assessment of adipose tissue compartments, hepatic steatosis, and diverticular disease and allows identification of patients who are at risk but in an asymptomatic disease state.

\section{Citation Format}

- Storz C, Rospleszcz S, Askani E et al. Magnetic Resonance Imaging of Diverticular Disease and its Association with Adipose Tissue Compartments and Constitutional Risk Factors in Subjects from a Western General Population. Fortschr Röntgenstr 2021; 193: 33-41

\section{Introduction}

Diverticular disease is one of the most common digestive conditions with a high prevalence globally, particularly in Western and industrialized countries [1-3]. Diverticular disease often affects the elderly population with a prevalence of up to $71 \%$ in individuals $\geq 80$ years [1]. Diverticular disease and its possible complications, such as bleeding or peritonitis are associated with risk fac- tors including obesity, smoking, and medications [4-8]. However, studies about the prevalence and risk factors of asymptomatic diverticular disease are scarce and thus, the underlying pathomechanism of asymptomatic diverticular disease and the association with constitutional risk factors are still not fully understood.

Various large-scale studies utilizing colonoscopy or computed tomography found an increasing prevalence of diverticulosis, due to multiple risk factors accelerating the development of diverticu- 
lar disease [1, 2, 9]. Previously, we demonstrated that magnetic resonance imaging (MRI) is a valid, reproducible, noninvasive modality for the assessment of diverticular disease and our initial results showed that asymptomatic diverticular disease is a common burden on healthcare system in the Western general population [10].

Different factors are associated with an increased risk of diverticular disease and its complications, for example inflammatory alterations, bleeding, and perforation. Beside risk factors, such as environmental factors, sex, age, and genetics, constitutional factors may be linked with the development of diverticular disease. More precisely, obesity with an increased body mass index (BMI), body weight, and abdominal fat represent risk factors for the development of diverticular disease and may even promote complicative disease stages $[5,11,12]$.

As studies in patients with asymptomatic diverticular disease are scarce and the underlying pathomechanism of the development of diverticular disease on the one hand and the genesis of inflammatory and complicative diverticular disease on the other hand might differ, further large-scale and population-based studies are warranted to gain deeper insight into the pathomechanism of diverticular disease and the potential to develop optimal individual prevention strategies.

Thus, the aim of the current study was to investigate the association between diverticular disease as measured by MRI and adipose tissue compartments, hepatic steatosis, and constitutional risk factors in a sample of an asymptomatic general Western population.

\section{Material and Methods}

\section{Study Design}

The design of the study as well as the sampling method and data collection were previously described in detail $[13,14]$. The study was performed as a cross-sectional prospective case-control study from a cohort of the 'Cooperative Health Research in the Augsburg Region, Germany' (KORA) for the purpose of investigating widespread diseases such as cardiovascular diseases and diabetes [13, 14]. Between 1999 and 2001, a large sample of the general population in the German region of Augsburg between 25 and 74 years old were recruited ('S4' cohort) $[13,14]$. Within the follow-up of the 'S4' cohort (so-called 'FF4' cohort) between June 2013 and September 2014 of the KORA study, eligible subjects were included in the study and whole-body MRI was performed $[13,14]$. Participants with prior cardiovascular disease (e. g. myocardial infarction or stroke) or participants with contraindications to intravenous administration of gadolinium were excluded [14]. Participants who met the following criteria were excluded: age $>72$, non-MRI-compatible implanted devices, breastfeeding or pregnant participants, as well as participants with impaired renal function (defined as a serum creatinine $\geq 1.3 \mathrm{mg} / \mathrm{dl}$ ) [14].

The study was approved by the institutional review board. Written informed consent was provided by all participants [14].

\section{Covariates}

To assess demographic variables and individual risk factors, comprehensive interviews and medical examination were performed, as described in detail elsewhere $[13,14]$. According to the definition of the World Health Organization, all participants were categorized according to their BMI (indicated as $\mathrm{kg} / \mathrm{m}^{2}$ ) as a) normal $\left(\mathrm{BMI}<25 \mathrm{~kg} / \mathrm{m}^{2}\right)$, b) overweight (BMI 25 to $<30 \mathrm{~kg} / \mathrm{m}^{2}$ ) and c) obese $\left(B M I \geq 30 \mathrm{~kg} / \mathrm{m}^{2}\right)$ [15].

\section{Magnetic Resonance Imaging Protocol and Imaging Analysis}

Imaging was performed on a 3 Tesla magnet Magnetom Skyra MRI system (Siemens Healthineers, Erlangen, Germany), as detailed elsewhere $[13,14]$. Extensive whole-body MRI was performed including protocols to assess alterations and anatomical characteristics of the brain, assessing, for instance, the cardiovascular system and cardiac function, body adipose content and anatomical characteristics of the chest and abdomen as well as hepatic or pancreatic adipose content [14]. All analyses were performed in a blinded fashion by independent readers.

\section{Assessment of Diverticular Disease}

The assessment and graduation system of diverticular disease was reported in detail elsewhere [10]. A T1-weighted 2-point isotropic VIBE-Dixon sequence (slice thickness: $1.7 \mathrm{~mm}$, spatial resolution: $1.7 \times 1.7 \mathrm{~mm}^{2}$, field of view: $488 \times 717 \mathrm{~mm}$ using a $256 \times 256 \mathrm{~mm}$ matrix, repetition time: $4.06 \mathrm{~ms}$, echo time: $1.26 ; 2.49 \mathrm{~ms}, 9^{\circ}$ flip angle) of the abdomen was employed for the assessment and evaluation of diverticular disease by counting diverticula potentially present in each colonic segment [10].

Diverticular disease was classified by a graded-scale to define the extent of diverticular disease, derived from the three-point quantitative scale used in a CT colonography study by de Cecco et al. $[10,16]$ : grade 1: no diverticular disease (no diverticula in all colonic segments), grade 2: mild diverticular disease (1-5 diverticula in at least one colonic segment), grade 3 : advanced diverticular disease ( $\geq 6$ diverticula in at least one colonic segment) [10]. A representative example of a participant with diverticular disease is provided in $>$ Fig. $\mathbf{1}$.

\section{Assessment of Adipose Tissue Compartments}

The isotropic VIBE-Dixon sequence was also acquired for the analysis and evaluation of abdominal adipose tissue compartments and adipose tissues were segmented semi-automatically, as described previously $[14,17,18]$. Thus, volumetric assessment of the subcutaneous adipose tissue (SAT) from the femoral head to the cardiac apex and visceral adipose tissue (VAT) from the femoral head to the cardiac apex was quantified by a fat selective tomogram using an in-house algorithm (based on Matlab R2013a). The total adipose tissue (TAT) results from the sum of subcutaneous and visceral adipose tissue (all indicated in liters) $[14,17$, 18]. 


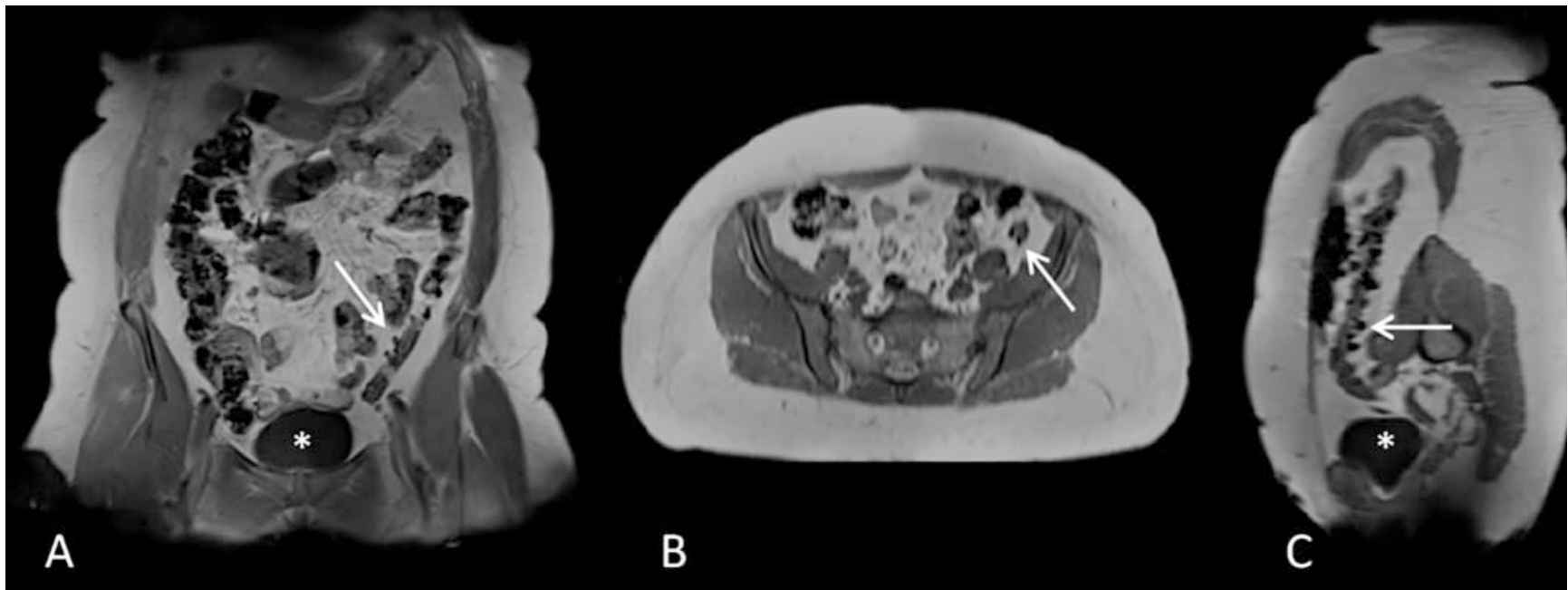

- Fig. 1 A coronal, B axial, C oblique reconstruction (T1w VIBE Dixon sequence). Example of a 65-year-old male undergoing the MRI study protocol. MRI images reveal multiple diverticula (exemplary white arrows) in the sigmoid colon. ${ }^{*}=$ urinary bladder.

- Abb. 1 A Koronare, B axiale, C schräge Rekonstruktion (T1w-VIBE-Dixon-Sequenz). Beispiel eines 65 Jahre alten Mannes. Die MRT-Bilder zeigen multiple Divertikel (exemplarisch weiße Pfeile) im Sigma. ${ }^{*}=$ Harnblase.

\section{Assessment of Hepatic Steatosis}

For the quantification of intrahepatic lipid content, a six-point Dixon-VIBE T1-weighted sequence was acquired and the intrahepatic fat fraction was assessed by manually drawing a region of interest on one slice in the liver parenchyma at the height of the portal vein using Osirix software (Vers. 4.1 64-bit, Pixmeo SARL, Bernex, GE, Switzerland) [14, 19]. Quantification of hepatic steatosis was indicated as the hepatic proton density fat fraction (PDFF) [14, 19].

\section{Statistical Analysis}

Demographic variables, individual risk factors, and volume of adipose tissue parameters of the participants are indicated as arithmetic mean and standard deviation or as median with first and third quartile for continuous covariates and as counts and percentages for categorical covariates. Differences in covariates between grades of diverticular disease were evaluated by ANOVA, KruskalWallis Rank-Sum-Test or $X^{2}$-Test, as appropriate. Differences in these covariates between participants with advanced diverticular disease and no disease were determined by $\mathrm{t}$-Test, $\mathrm{X}^{2}$-Test and Wilcoxon-Test and resulting $\mathrm{p}$-values were Bonferroni-corrected for multiple testing. Associations of BMI and adipose tissue parameters with the presence of diverticular disease were assessed by logistic regression models adjusted for age and sex. Odds Ratios (OR) with corresponding 95\% confidence intervals ( $\mathrm{Cl}$ ) are calculated per standard deviation of the variable of interest.

\section{Results}

Overall, 400 participants were enrolled in the study. 29 participants were excluded from the study analysis due to incomplete MRI data sets of the included sequences (7.3\%). Overall, 371 participants formed the analysis cohort (mean age: $56.2 \pm 9.2$ years, $58.2 \%$ male). A study flowchart is presented in detail in $\mathbf{F i g .} \mathbf{2}$.

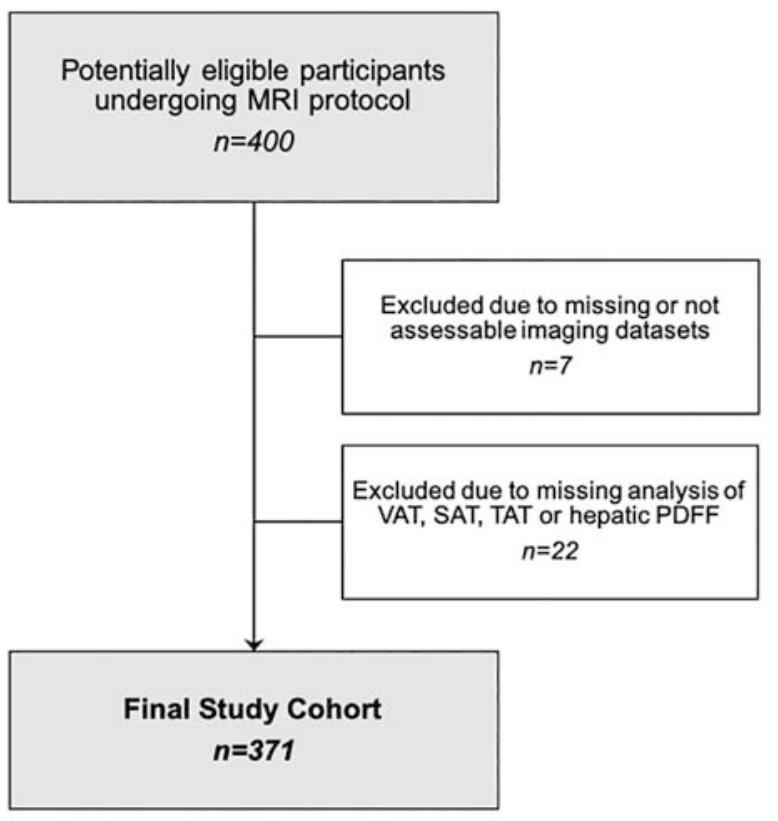

- Fig. 2 Study flowchart of participant inclusion and exclusion. VAT = visceral adipose tissue, SAT = subcutaneous adipose tissue, TAT $=$ total adipose tissue, PDFF = proton density fat fraction.

- Abb. 2 Flussdiagramm der Studie mit Einschluss- und Ausschlusskriterien der Studienteilnehmer. VAT = visceral adipose tissue (viszerales Fettkompartiment); SAT = subcutaneous adipose tissue (subkutanes Fettkompartiment); TAT = total adipose tissue (totals Fettkompartiment); PDFF = proton density fat fraction 
- Table 1 Subject demographics and risk factors according to the grade of diverticular disease.

- Tab.1 Demografische Charakteristiken und Risikofaktoren der Probanden im Zusammenhang mit dem Ausmaß der Divertikulose.

\begin{tabular}{|c|c|c|c|c|c|c|}
\hline & \multirow[b]{2}{*}{ all } & \multicolumn{3}{|c|}{ diverticular disease } & \multirow[b]{2}{*}{$\begin{array}{l}\text { p-value } \\
\text { (all) }\end{array}$} & \multirow[b]{2}{*}{ p-value* } \\
\hline & & no & mild & advanced & & \\
\hline N & 371 & 217 & 92 & 62 & & \\
\hline age (years) & $56.2 \pm 9.2$ & $54.3 \pm 8.9$ & $56.8 \pm 9.2$ & $61.7 \pm 7.7$ & $<0.001$ & $<0.001$ \\
\hline men & $216(58.2 \%)$ & $121(55.8 \%)$ & $54(58.7 \%)$ & $41(66.1 \%)$ & 0.34 & 0.38 \\
\hline BMI (kg/m2) & $27.9 \pm 4.7$ & $27.5 \pm 4.6$ & $27.3 \pm 4.3$ & $29.9 \pm 5.1$ & $<0.001$ & $<0.001$ \\
\hline - normal & $104(28.0 \%)$ & $62(28.6 \%)$ & $31(33.7 \%)$ & $11(17.7 \%)$ & 0.013 & 0.019 \\
\hline " overweight & $159(42.9 \%)$ & $97(44.7 \%)$ & $40(43.5 \%)$ & $22(35.5 \%)$ & & \\
\hline - obese & $108(29.1 \%)$ & $58(26.7 \%)$ & $21(22.8 \%)$ & $29(46.8 \%)$ & & \\
\hline total cholesterol (mg/dL) & $217.4 \pm 36.4$ & $213.9 \pm 35.3$ & $221.2 \pm 40.3$ & $224.0 \pm 33.1$ & 0.08 & 0.11 \\
\hline HDL cholesterol (mg/dL) & $61.8 \pm 17.7$ & $62.7 \pm 17.9$ & $63.1 \pm 18.8$ & $56.8 \pm 14.7$ & 0.05 & 0.043 \\
\hline LDL cholesterol (mg(dL) & $139.1 \pm 32.9$ & $135.1 \pm 32.7$ & $142.2 \pm 34.4$ & $148.7 \pm 29.0$ & 0.009 & 0.008 \\
\hline triglycerides (mg/dL) & $132.1 \pm 86.8$ & $129.2 \pm 93.4$ & $126.9 \pm 79.1$ & $150.1 \pm 70.9$ & 0.20 & 0.20 \\
\hline $\begin{array}{l}\text { systolic blood pressure } \\
(\mathrm{mmHg})\end{array}$ & $120.7 \pm 16.5$ & $118.1 \pm 15.6$ & $121.4 \pm 18.7$ & $128.7 \pm 13.8$ & $<0.001$ & $<0.001$ \\
\hline $\begin{array}{l}\text { diastolic blood pressure } \\
(\mathrm{mmHg})\end{array}$ & $75.4 \pm 9.9$ & $74.8 \pm 9.0$ & $74.7 \pm 12.0$ & $78.4 \pm 9.3$ & 0.033 & 0.025 \\
\hline antihypertensive medication & 90 (24.3\%) & $38(17.5 \%)$ & $25(27.2 \%)$ & 27 (43.5\%) & $<0.001$ & $<0.001$ \\
\hline antithrombotic drugs & $21(5.7 \%)$ & $6(2.8 \%)$ & $10(10.9 \%)$ & $5(8.1 \%)$ & 0.013 & 0.26 \\
\hline
\end{tabular}

Variables as mean and standard deviation or number and percentage. BMI = body mass index, $\mathrm{HDL}=$ high-density lipoprotein, LDL =low-density lipoprotein; * advanced vs. no diverticular disease

Information about demographical variables of the study population are provided in $>$ Table 1.

\section{Prevalence of Diverticular Disease based on MRI}

Overall, the prevalence of diverticular disease was high (prevalence: $154 / 371,41.5 \%$ ) with $24 \%$ of all participants exhibiting mild and $17 \%$ exhibiting advanced diverticular disease (92/371 and 62/371, respectively).

\section{Constitutional Factors and Adipose Tissue}

In contrast to subjects without diverticular disease, subjects with diverticular disease had a significantly higher BMI $(29.9 \pm 5.1 \mathrm{~kg} /$ $\mathrm{m}^{2}$ vs. $27.3 \pm 4.3 \mathrm{~kg} / \mathrm{m}^{2}$ vs. $27.5 \pm 4.6 \mathrm{~kg} / \mathrm{m}^{2}$ for participants with advanced vs. mild vs. without diverticular disease, $p<0.001)$. Participants with diverticular disease had higher VAT values compared to those without diverticular disease (VAT: $6.0 \pm 2.8 \mathrm{I}$ vs. $4.1 \pm 2.4$ I vs. $4.2 \pm 2.6$ I for participants with advanced vs. mild vs. without diverticular disease, respectively, all $p<0.001)$. Additionally, SAT values were higher in participants with diverticular disease compared to those without (SAT: $9.2 \pm 3.6$ I vs. $7.8 \pm 3.4$ I vs. $7.8 \pm 3.6$ I for participants with advanced vs. mild vs. without diverticular disease, respectively; all p<0.02, > Fig. 3 and - Table 2). The percentage of hepatic PDFF was significantly higher in participants with diverticular disease, especially advanced di- verticular disease $(4.9 \%[2.7,11.4]$ vs. $5.0 \%[3.1,9.7]$ vs. $8.1 \%$ $[5.5,14.6]$ for participants without vs. mild vs. advanced diverticular disease, respectively; $p=0.002$, > Fig. 3 and $>$ Table 2).

VAT and SAT were strongly associated with an increased risk of advanced diverticular disease, independent of sex and age (VAT: OR 1.64, $95 \% \mathrm{Cl}[1.17,2.32]$, > Table 3). Also, SAT was independently associated with advanced diverticular disease after an adjustment for age and sex (SAT: OR 1.77, $95 \% \mathrm{Cl}[1.29,2.43]$, - Table 3).

\section{Discussion}

We investigated the association between the presence and degree of diverticular disease and hepatic steatosis and constitutional risk factors in a general Western population. Our results show a significant association between asymptomatic advanced diverticular disease and increased BMI and obesity with an elevated amount of adipose tissue.

There is a large body of evidence that the prevalence of colonic diverticula increases with age and in Western populations most of the colonic diverticula are located in the left-sided colonic segments $[1,2,10,16,20]$. A classic hypothesis assumes a link between dietary habits (e. g. low-fiber intake) as well as high intraluminal pressure leading to herniation of the mucosa in weak seg- 

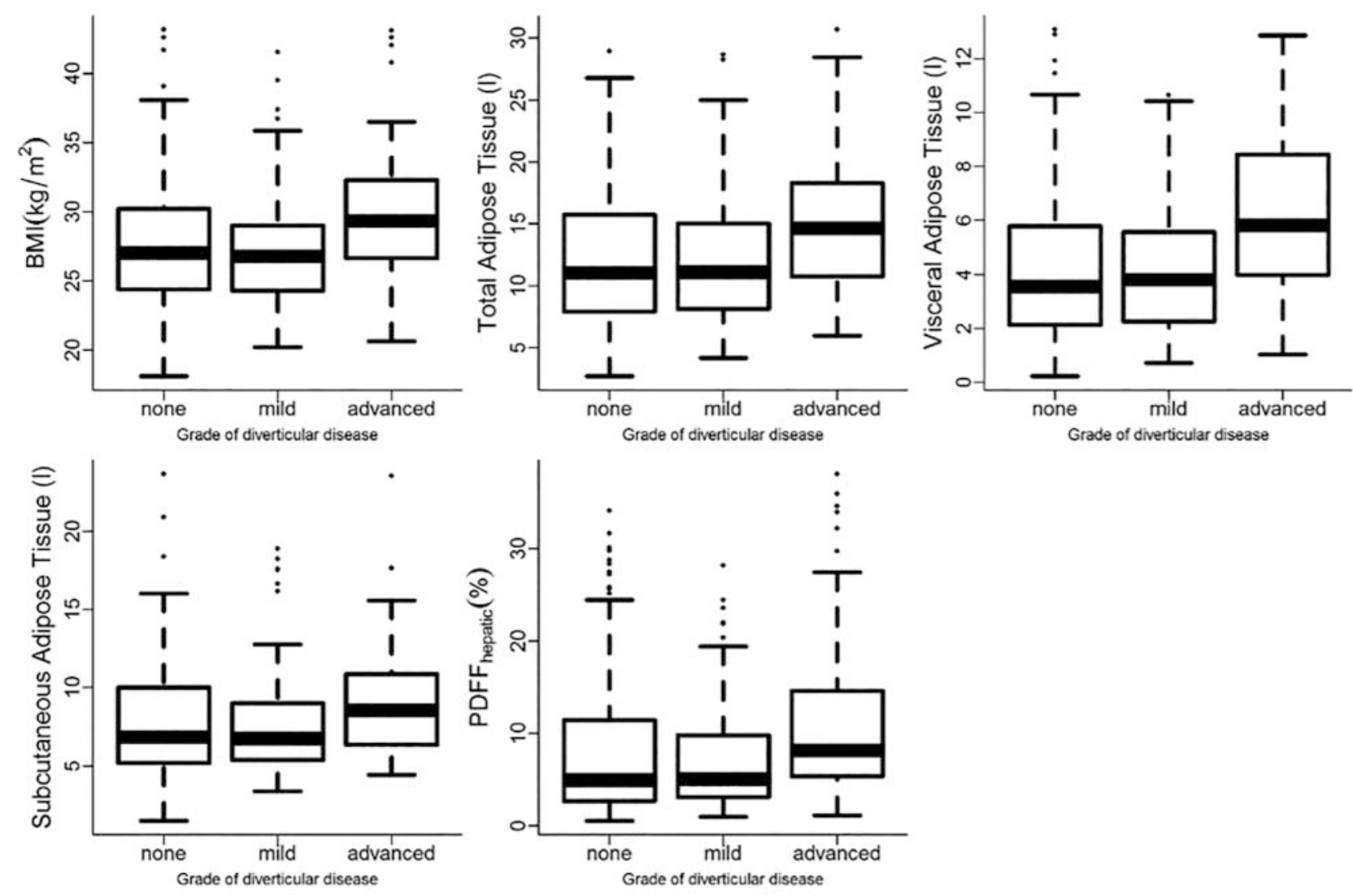

- Fig. 3 Differences in body mass index (BMI) and MRI-based total, visceral, and subcutaneous adipose tissue and hepatic steatosis (indicated in hepatic proton density fat fraction (PDFF)) between participants with no, mild, or advanced diverticular disease.

- Abb. 3 Unterschiede des Body-Mass-Index (BMI) und der MRI-basierten totalen, viszeralen und subkutanen Fettkompartimente sowie der Hepatosteatose (gemessen in hepatic proton density fat fraction (PDFF)) zwischen Studienteilnehmern ohne, mit mäßiger oder mit fortgeschrittener Divertikulose.

ments of the colonic muscular layers [21]. Furthermore, several studies demonstrated a significant correlation between obesity and the presence of diverticular disease [22]. However, the underlying pathomechanism of the development of diverticular disease is not fully understood yet. Furthermore, these findings are often related with inflammatory alterations or complicative diverticular disease [5, 11, 12]. In a prospective single-center study, Nagata et al. found an association between increased VAT as well as hepatic steatosis and asymptomatic diverticular disease [23]. Our results confirm an association between increased amounts of adipose tissues and the presence of advanced diverticular disease. Furthermore, our results suggest that hepatic steatosis may be associated with advanced diverticular disease, however, these results were not independent of age and sex. Therefore, it is likely that our findings can be attributed to the metabolic alterations in obese patients resulting in a shared pathological pathway of cardiometabolic disorders [24]. Furthermore, as VAT and central obesity, determined by MRI, are known as pathogenic fat depots and an excess of VAT and hepatic PDFF seems to be linked with cardiometabolic risk and higher mortality, a relationship between the development of diverticular disease in subjects with increased BMI, SAT, VAT and higher amounts of hepatic fat, carrying a higher metabolic risk, appears to be quite reasonable. This consideration is in line with the study results found in a nationwide inpatient sample, as Reddy et al. found an association between nonalcoholic fatty liver disease and diverticular disease, inflammatory gastrointestinal disorders as well as gallstone and benign inflammatory pancreatic disorders [24]. Furthermore, several studies found a link between cardiovascular diseases and nonalcoholic fatty liver disease and suggest a relationship in the etiological pathway between the development of hepatic steatosis and cardiovascular diseases [25, 26]. These results suggest a shared pathomechanism between nonalcoholic fatty liver disease, gastrointestinal disorders, cardiovascular risk factors and the metabolic syndrome. Several studies assume an association of altered gut bacterial flora in obesity which leads to a higher concentration of intestinal methane, resulting in increased intraluminal pressure which contributes to the development of diverticular formations [22, 27-29]. Additionally, VAT has often been reported as pathogenic fat depot and endocrine organ producing a variety of several proteins and 
- Table 2 Constitutional factors and MRI-based amount of adipose tissue of the study participants according to the grade of diverticular disease.

- Tab.2 Konstitutionelle Faktoren und MRT-basierte Menge der Fettkompartimente der Studienteilnehmer in Abhängigkeit des Ausmaßes der Divertikulose.

\begin{tabular}{|c|c|c|c|c|c|c|}
\hline \multicolumn{7}{|c|}{ diverticular disease } \\
\hline & all & no & mild & advanced & $\begin{array}{l}\text { p-value } \\
\text { (all) }\end{array}$ & p-value* \\
\hline & $N=371$ & $N=217$ & $\mathrm{~N}=92$ & $N=62$ & & \\
\hline $\mathrm{BMI}\left(\mathrm{kg} / \mathrm{m}^{2}\right)$ & $27.9 \pm 4.7$ & $27.5 \pm 4.6$ & $27.3 \pm 4.3$ & $29.9 \pm 5.1$ & $<0.001$ & $<0.001$ \\
\hline TAT (liters) & $12.5 \pm 5.3$ & $12.0 \pm 5.3$ & $11.9 \pm 5.0$ & $15.3 \pm 5.4$ & $<0.001$ & $<0.001$ \\
\hline VAT (liters) & $4.5 \pm 2.7$ & $4.2 \pm 2.6$ & $4.1 \pm 2.4$ & $6.0 \pm 2.8$ & $<0.001$ & $<0.001$ \\
\hline SAT (liters) & $8.0 \pm 3.6$ & $7.8 \pm 3.6$ & $7.8 \pm 3.4$ & $9.2 \pm 3.6$ & 0.016 & 0.013 \\
\hline hepatic PDFF (\%) & $5.6[2.9,11.7]$ & $4.9[2.7,11.4]$ & $5.0[3.1,9.7]$ & $8.1[5.5,14.6]$ & 0.002 & 0.002 \\
\hline
\end{tabular}

Variables as mean and standard deviation or percent and $95 \%$ confident interval. TAT = total adipose tissue, VAT = visceral adipose tissue, SAT = subcutaneous adipose tissue, PDFF = proton density fat fraction. * advanced vs. no diverticular disease

- Table 3 Association of constitutional risk factors with presence of diverticular disease adjusted for age and sex.

- Tab.3 Zusammenhang konstitutioneller Risikofaktoren mit Vorhandensein einer Divertikulose, adjustiert für Alter und Geschlecht.

\begin{tabular}{|c|c|c|c|c|c|c|}
\hline & \multicolumn{3}{|c|}{ outcome no vs. any diverticular disease } & \multicolumn{3}{|c|}{ outcome no vs. advanced diverticular disease } \\
\hline & OR & $95 \% \mathrm{Cl}$ & $\mathbf{p}$ & OR & $95 \% \mathrm{Cl}$ & $\mathbf{p}$ \\
\hline \multicolumn{7}{|c|}{ measures of adipose tissue } \\
\hline TAT (I) & 1.17 & {$[0.94,1.46]$} & 0.148 & 1.76 & {$[1.29,2.41]$} & $<0.001$ \\
\hline VAT (I) & 1.12 & {$[0.86,1.45]$} & 0.403 & 1.64 & {$[1.17,2.32]$} & 0.005 \\
\hline SAT (I) & 1.20 & {$[0.96,1.5]$} & 0.102 & 1.77 & {$[1.29,2.43]$} & $<0.001$ \\
\hline log (hepatic PDFF (\%)) & 1.06 & {$[0.84,1.34]$} & 0.614 & 1.35 & {$[0.98,1.86]$} & 0.07 \\
\hline $\mathrm{BMI}\left(\mathrm{kg} / \mathrm{m}^{2}\right)$ & 1.18 & {$[0.95,1.46]$} & 0.141 & 1.69 & {$[1.24,2.29]$} & 0.001 \\
\hline
\end{tabular}

adipocytokines. Increased VAT und thus an increased amount of adipocytes lead to an accumulation of dysregulated secretion of several proteins and cytokines resulting in an imbalance of proand anti-inflammatory adipocytokines [30]. For example, several studies found an inverse association between adiponectin and an excess of VAT, and in turn, lower adiponectin levels seem to be associated with metabolic disorders such as cardiovascular diseases and diabetes [31]. As an increase of pro-inflammatory cytokines and a decrease of anti-inflammatory cytokines in obese states promote the development of cardiovascular disease and diabetes due to alterations of endothelial cells and cardiomyocytes (e. g. cell injury, myocytes death, and ischemic injury), an altera- tion of colonic epithelium and mucosa can be strongly assumed. However, one might speculate that the development of diverticular disease as well as other metabolic alterations in obese subjects are the result of a multifactorial pathomechanism additionally including nutritional, genetic, and lifestyle factors.

Our study found a strong link between the presence of asymptomatic advanced diverticular disease and constitutional risk factors, e. g. increased BMI, VAT, and hepatic PDFF. As we previously showed, advanced diverticular disease is also associated with age and more interestingly, participants with left-sided diverticular disease have a higher BMI and are older [10]. Overall, our findings lead to the presumption that advanced diverticular disease in left- 
sided colonic segment seems to be acquired rather than congenital and its etiology seems to be linked with cardiometabolic risk factors. As obesity increases the risk of inflammatory diverticular disease, complicative courses of diseases and cardiometabolic risk factors increase and may similarly be associated with higher hospitalization rates and morbidity [5, 12]. Hence, the detection of asymptomatic diverticular disease and cardiometabolic risk factors, such as increased adipose tissues and hepatic steatosis, could improve patient-tailored risk stratification.

Our study has several limitations. Our initial study design was focused on the assessment of cardiometabolic multi-organ alterations in a general Western population. The MRI protocol was not tailored to the assessment of diverticular disease. However, the determination of diverticula in the colonic segments was shown to be feasible as previously reported [10]. Only 62 of the 371 subjects included in our study (17\%) had advanced diverticular disease. Therefore, the statistical data reported in our study only refers to a small part of the study sample. Furthermore, outcome data on the development of inflammatory alterations or complicative diverticular disease were missing.

In conclusion, our study showed that a higher BMI as well as an excess of SAT and VAT as determined by MRI are associated with the presence of asymptomatic advanced diverticular disease. Given the significant health burden of diverticular disease and the lack of studies about asymptomatic diverticular disease, our findings may add important information to improve the understanding of the underlying pathomechanism and this may have high relevance for patient risk stratification. Additionally, our results indicate that MRI represents a feasible modality for the assessment of diverticular disease and constitutional risk factors such as central obesity and hepatic steatosis and may serve as a valuable noninvasive tool for the identification of a high-risk MRI phenotype of advanced diverticular disease. Further research in larger cohorts is warranted to get better insight into the pathomechanism of diverticular disease and its threatening complications.

\section{CLINICAL RELEVANCE}

- Asymptomatic advanced diverticular disease seems to be associated with cardiometabolic alterations such as constitutional risk factors (e. g. BMI) and an excess of adipose tissue compartments.

- Our study results may contribute to a better understanding of the underlying pathological pathway of cardiometabolic alterations and diverticular disease.

- MRI represents a noninvasive tool for the assessment of diverticular disease and cardiometabolic alterations, and thus enables an improvement in the risk stratification of asymptomatic patients.

\section{Funding}

German Federal Ministry of Education and Research BMBF

German Centre for Diabetes Research, Neuherberg

Deutsche Forschungsgemeinschaft

German Centre for Cardiovascular Disease Research

\section{Conflict of Interest}

Fabian Bamberg: Speakers Bureau - Siemens Healthineers, Bayer Healthcare; Unrestricted Research Grants - Siemens Healthineers, Bayer Healthcare.

\section{References}

[1] Everhart JE, Ruhl CE. Burden of digestive diseases in the United States part II: lower gastrointestinal diseases. Gastroenterology 2009; 136: 741-754. doi:10.1053/j.gastro.2009.01.015

[2] Wang FW, Chuang HY, Tu MS et al. Prevalence and risk factors of asymptomatic colorectal diverticulosis in Taiwan. BMC Gastroenterol 2015; 15: 40. doi:10.1186/s12876-015-0267-5

[3] Peery AF, Keku TO, Martin CF et al. Distribution and Characteristics of Colonic Diverticula in a United States Screening Population. Clin Gastroenterol Hepatol 2016; 14: 980-985, e981. doi:10.1016/ j.cgh.2016.01.020

[4] Crowe FL, Appleby PN, Allen NE et al. Diet and risk of diverticular disease in Oxford cohort of European Prospective Investigation into Cancer and Nutrition (EPIC): prospective study of British vegetarians and non-vegetarians. BMJ 2011; 343: d4131. doi:10.1136/bmj.d4131

[5] Strate LL, Liu YL, Aldoori WH et al. Obesity increases the risks of diverticulitis and diverticular bleeding. Gastroenterology 2009; 136: 115-122, e111. doi:10.1053/j.gastro.2008.09.025

[6] Usai P, Ibba I, Lai M et al. Cigarette smoking and appendectomy: effect on clinical course of diverticulosis. Dig Liver Dis 2011; 43: 98-101. doi:10.1016/j.dld.2010.05.008

[7] Feuerstein JD, Falchuk KR. Diverticulosis and Diverticulitis. Mayo Clin Proc 2016; 91: 1094-1104. doi:10.1016/j.mayocp.2016.03.012

[8] Faucheron JL, Roblin X, Bichard P et al. The prevalence of right-sided colonic diverticulosis and diverticular haemorrhage. Colorectal Dis 2013; 15: e266-270. doi:10.1111/codi.12137

[9] Yamamichi N, Shimamoto T, Takahashi Y et al. Trend and risk factors of diverticulosis in Japan: age, gender, and lifestyle/metabolic-related factors may cooperatively affect on the colorectal diverticula formation. PLoS One 2015; 10: e0123688. doi:10.1371/journal.pone.0123688

[10] Storz C, Rothenbacher T, Rospleszcz S et al. Characteristics and associated risk factors of diverticular disease assessed by magnetic resonance imaging in subjects from a Western general population. Eur Radiol 2018. doi:10.1007/s00330-018-5687-5

[11] Kopylov U, Ben-Horin S, Lahat A et al. Obesity, metabolic syndrome and the risk of development of colonic diverticulosis. Digestion 2012; 86: 201-205. doi:10.1159/000339881

[12] Hjern F, Wolk A, Hakansson N. Obesity, physical inactivity, and colonic diverticular disease requiring hospitalization in women: a prospective cohort study. Am J Gastroenterol 2012; 107: 296-302. doi:10.1038/ ajg.2011.352

[13] Holle R, Happich M, Lowel H et al. KORA - a research platform for population based health research. Gesundheitswesen 2005; 67 (Suppl. 1): S19-25. doi:10.1055/s-2005-858235

[14] Bamberg F, Hetterich H, Rospleszcz S et al. Subclinical Disease Burden as Assessed by Whole-Body MRI in Subjects With Prediabetes, Subjects With Diabetes, and Normal Control Subjects From the General Population: The KORA-MRI Study. Diabetes 2017; 66: 158-169

[15] [Anonym]. Obesity: preventing and managing the global epidemic. Report of a WHO consultation. World Health Organ Tech Rep Ser 2000; 894: i-xii, 1-253

[16] De Cecco CN, Ciolina M, Annibale B et al. Prevalence and distribution of colonic diverticula assessed with CT colonography (CTC). Eur Radiol 2016; 26: 639-645. doi:10.1007/s00330-015-3866-1 
[17] Storz C, Heber SD, Rospleszcz S et al. The role of visceral and subcutaneous adipose tissue measurements and their ratio by magnetic resonance imaging in subjects with prediabetes, diabetes and healthy controls from a general population without cardiovascular disease. The British Journal of Radiology 2018; 0: 20170808. doi:10.1259/ bjr.20170808

[18] Lorbeer R, Rospleszcz S, Schlett CL et al. Correlation of MRI-derived adipose tissue measurements and anthropometric markers with prevalent hypertension in the community. Journal of hypertension 2018; 36 : 1555-1562

[19] Lorbeer R, Bayerl C, Auweter S et al. Association between MRI-derived hepatic fat fraction and blood pressure in participants without history of cardiovascular disease. Journal of hypertension 2017; 35: 737-744

[20] Peery AF. Recent Advances in Diverticular Disease. Curr Gastroenterol Rep 2016; 18: 37. doi:10.1007/s11894-016-0513-1

[21] Painter NS, Burkitt DP. Diverticular disease of the colon: a deficiency disease of Western civilization. Br Med J 1971; 2: 450-454

[22] Wijarnpreecha K, Ahuja W, Chesdachai S et al. Obesity and the Risk of Colonic Diverticulosis: A Meta-analysis. Dis Colon Rectum 2018; 61: 476-483. doi:10.1097/DCR.0000000000000999

[23] Nagata N, Sakamoto K, Arai T et al. Visceral Abdominal Obesity Measured by Computed Tomography is Associated With Increased Risk of Colonic Diverticulosis. J Clin Gastroenterol 2015; 49: 816-822. doi:10.1097/MCG.0000000000000267
[24] Reddy SK, Zhan M, Alexander HR et al. Nonalcoholic fatty liver disease is associated with benign gastrointestinal disorders. World J Gastroenterol 2013; 19: 8301-8311. doi:10.3748/wjg.v19.i45.8301

[25] Ma J, Hwang SJ, Pedley A et al. Bi-directional analysis between fatty liver and cardiovascular disease risk factors. J Hepatol 2017; 66: 390-397. doi:10.1016/j.jhep.2016.09.022

[26] Targher G, Day CP, Bonora E. Risk of cardiovascular disease in patients with nonalcoholic fatty liver disease. N Engl J Med 2010; 363: 13411350. doi:10.1056/NEJMra0912063

[27] Yazici C, Arslan DC, Abraham R et al. Breath Methane Levels Are Increased Among Patients with Diverticulosis. Dig Dis Sci 2016; 61: 2648 2654. doi:10.1007/s10620-016-4174-6

[28] Weaver GA, Krause JA, Miller TL et al. Incidence of methanogenic bacteria in a sigmoidoscopy population: an association of methanogenic bacteria and diverticulosis. Gut 1986; 27: 698-704. doi:10.1136/ gut.27.6.698

[29] Basseri R], Basseri B, Pimentel M et al. Intestinal methane production in obese individuals is associated with a higher body mass index. Gastroenterol Hepatol (NY) 2012; 8: 22-28

[30] Ouchi N. Adipocytokines in Cardiovascular and Metabolic Diseases. J Atheroscler Thromb 2016; 23: 645-654. doi:10.5551/jat.34918

[31] Matsuzawa Y. Therapy Insight: adipocytokines in metabolic syndrome and related cardiovascular disease. Nat Clin Pract Cardiovasc Med 2006; 3: 35-42. doi:10.1038/ncpcardio0380 